\title{
8 Conclusions
}

The nearly two centuries of the existence of the Tangut state witnessed the development of a sophisticated Tangut literary culture. Contrary to some earlier explanations, the Mongol onslaught did not wipe out the Tangut cities and annihilate the local population, at least not completely. Although the Tanguts ceased to exist as a state, the language continued to be used for decades or perhaps even centuries after the Mongols took control of the region. Little is known about the particulars of this later phase in the history of the Tanguts but there are numerous examples of administrative documents and Buddhist texts, both from Khara-khoto and other sites, which are written in Tangut yet postdate the fall of the Tangut state. These remnants attest to the survival of segments of population who were either fully literate in Tangut or, as this may have been the case in the Ming period, used the script in specific contexts.

Unquestionably, one of the greatest achievements of Tangut culture was the invention of a native script, which at the time was a decidedly political move intended to symbolise the autonomy of the new Tangut state. Skilfully manoeuvring between his two powerful neighbours, the Song and the Liao, Emperor Yuanhao managed to build up sufficient military and political strength to claim independence and shake off the direct control of both states. The introduction of the Tangut script was part of the efforts to curtail the dependence on the Chinese (and possibly Khitan) scripts. Literacy and writing in general was closely connected with governing the state and running a functional administration, and to do this with the help of the Chinese script would have inevitably implied some form of subordinate relationship with China. The creation of a native script, in turn, signified that the Tanguts were no longer barbarians who had no writing system of their own, which was a common cliché in traditional historiographical works when describing China's uncivilised neighbours. The choice to design a script on the basis of the Chinese model, rather than using the Tibetan syllabary or one of the Central Asian alphabets that may have been better suited to write the Tangut language, evidently also derived from the desire to have a writing system comparable to, yet different from, Chinese characters.

Immediately after the introduction of the new script, work began on producing texts written in Tangut. The translation of the Chinese Buddhist canon was a project that required an extraordinary dedication of resources and which yielded thousands of titles within a few decades. The exceptional efforts directed at translating and disseminating Buddhist texts are also evidenced in the surviving Tangut material, in which Buddhist scriptures comprise by far the largest portion. At the same time, the Tanguts also translated many secular texts from 
Chinese and these attest to the significance of Confucian learning at specific periods during the history of the Tangut state. One of the important genres among the secular texts is that of primers and other types of educational works, which, once again, reveal the indebtedness of Tangut literacy to the Chinese written tradition. In many cases those who learned to read and write in Tangut would have also become familiar with the Chinese literary past, even if through Tangut translations of those.

A related phenomenon that seems to further underline the dependence on the Chinese tradition is the scarcity of native texts among the surviving Tangut texts. While this may be partially determined by the nature and function (whatever that may have been) of the library stupa in Khara-khoto, the Tangut and Chinese books excavated from other sites in northwest China show a similar picture. A possible explanation for the dearth of native texts may be the relatively short time between the invention of the script and the end of the $12^{\text {th }}$ century, the period when most of the surviving manuscripts and books are thought to have been produced. Yet even this stretch of time amounts to over 160 years, which would have been more than enough to build up a collection of native texts. Another possible answer is the nature of the collections discovered so far, all of which come from Buddhist sites and thus consist of predominantly Buddhist material. It is undeniable that writing and literacy in the Tangut state, as it was also the case in Dunhuang and Turfan, were closely tied with religion, yet it is still possible that a discovery of a site of secular nature may yield completely different results.

By far the largest portion of extant Tangut texts comprise translations. In most cases, the source language was Chinese but there are also many Buddhist texts of Tibetan origin. In addition, Chinese translations of Tibetan Tantric texts survive in manuscript form among the Khara-khoto material. In contrast with this, there seem to have been no secular texts translated from Tibetan. Therefore, not counting the very meagre number of native Tangut texts, it seems that, as a rule, secular texts were translated from Chinese. These translations include Confucian classics both with and without commentaries, texts on military strategy, popular encyclopaedias, popular histories, primers and other types of educational texts. Taken together, these works comprise a considerable body of texts which are significant not only for scholars working on Tangut history and language but also for researchers in other fields.

First, Tangut versions of Chinese texts have been invaluable for the decipherment of Tangut, and remain to be important for working out the particulars of grammar and syntax. Having a large corpus of parallel texts is of major help in understanding an unknown language and this has indeed been one of the 
main avenues of research at the early stages of Tangut studies. In this respect, Buddhist texts are also useful even if their language often differs from that of secular works, betraying a heavier influence of Chinese syntax. Secular texts are believed to be less dependent on the wording of the original and thus may be more representative of ordinary Tangut spoken at the time. We should also note that the reliance on parallel Chinese texts in the process of deciphering Tangut is perhaps the main reason why our current understanding of Tangut is so dependent on Chinese and why in many cases researchers in effect read Tangut texts by transcribing and glossing those in Chinese.

Second, Tangut translations of secular works have a high but largely untapped potential for the traditional field of sinology. In fact, the aim of the present book is to bring this material to the attention of scholars working with Chinese texts by showing its significance beyond the narrow circle of Tangut studies. Here we have a sizeable body of texts dating to the $11^{\text {th }}-12^{\text {th }}$ centuries, translated from Chinese originals that circulated in northern China. This is the largest collection of "Chinese" texts from this period excavated from a single location, even if they are technically not in Chinese. On the most basic level, together with Chinese-language books and manuscripts found at Khara-khoto, the Tangut material tells us what texts were in use at this time, even if this information will mostly pertain to the north-western periphery of China. In this respect the situation is similar to the collections of Chinese texts preserved in Dunhuang and other East Asian countries, such as Korea and Japan.

Many of these works are known in their Chinese original, others are either known by their title only or completely unknown. Even the translations for which we have extant Chinese versions can preserve a number of interesting features that may have been lost in the Chinese versions. One such example is the Tangut version of the military treatise Liutao, which contains two additional sections that are not part of the transmitted Chinese versions, all of which derive from the Song military canon. The fact that fragments of these two sections can be located as quotes in medieval encyclopaedias attests to the existence of alternate versions of the Liutao which still contained the two lost sections. Therefore, the Tangut book discovered by Kozlov in Khara-khoto provides precious textual evidence that is unavailable from Chinese language editions.

Another example is the Tangut translation of the Sunzi, which has three commentaries. Even though the manuscript version of the translation omits the commentaries, the title identifies it as a three-commentary edition. The printed version of the translation has the same title and, indeed, includes the text of the three commentaries. Such an edition does not survive in the Chinese tradition where the Sunzi only comes with one, ten or eleven commentaries. While it is 
theoretically possible that the ten-commentary Tangut edition was compiled by a Tangut editor or translator through the process of eliminating some of the commentaries from a Chinese edition with ten or eleven-commentaries, it seems more likely that it was based on a now lost Chinese edition which had only three commentaries. Accordingly, the discovery of the Tangut translation revealed the possible existence of such an edition in the Song period and, at the same time, provided evidence to a greater diversity of editions in the medieval and early modern periods.

The Tangut translations may also shed light on the naming of books, which is especially valuable when the extant Chinese editions have dissimilar titles. For example, the note at the end of the Tangut manuscript of the General's Garden supplies key information for solving the question of the original title of the treatise, known in Chinese sources under three distinct titles as Xinshu (Book of Heart), Xinshu (New Book) and Jiangyuan (General's Garden). Albeit in a foreign language, the Tangut translation represents the first known edition of this work and identifies it under the title that matches the Chinese title Jiangyuan. Naturally, this does not prove conclusively that the other titles were not in use at this time but at least evidences the existence of the title Jiangyuan during the Song period.

In many cases the Tangut translations feature works the Chinese original of which survived only partially. A notable example is the Tang encyclopaedia called Forest of Categories (Leilin) fragments of which were discovered among the Dunhuang manuscripts, and a printed Tangut edition of which was also found in Khara-khoto. The Tangut text furnishes a wealth of material unavailable in the Chinese fragments and is therefore of great help when trying to reconstruct the original text. Since such encyclopaedias typically consist of stories based on earlier sources, in many cases the wording of the original may be approximated quite accurately. In addition, as a witness of an early encyclopaedia, the Tangut translation of the Forest of Categories is of major significance for studying the origin and development of the entire genre.

Finally there are several Tangut books and manuscripts with texts that did not survive in Chinese. While in principle some of these may be native Tangut compositions, their nature and content often points to a Chinese origin. As sole witnesses of particular compositions, they are valuable for Chinese philology even in translations which can help reconstruct the wording of the originals only tentatively. There is no doubt that for at least some of these texts the Chinese originals are extant and we simply have not been able to identify them yet. Future researchers will probably be able to make these identifications. Other texts will continue to be known only in translation, either by their Tangut title 
(if available) or under a title assigned to them by modern researchers. It is also possible that in some cases we will be able to ascertain that Tangut texts that survive as separate books and manuscripts represent pieces of the same work or different editions of the same work. Thus the Stein collection of Tangut material at the British Library consists of thousands of fragments and many of these have been identified as belonging to books kept in St. Petersburg. The obvious reason for this is that when Stein visited Khara-khoto in 1914, it had already been excavated by the Russian expedition and he could only collect the fragments left behind. Accordingly, both collections come from the same place and there should be many more fragments that can be joined together. The publication of the complete collections from London and St. Petersburg will no doubt lead to the identification of additional fragments.

In sum, the Tangut books and manuscripts discovered at Khara-khoto and other sites of the ancient Tangut domain contain a sizeable body of Chinese texts in Tangut translation. In a sense, these finds provide access to what is probably the largest collection of Chinese texts from the $11^{\text {th }}-12^{\text {th }}$ centuries, and even if access is hindered by a language barrier, most of these texts are by now available in annotated translations. Unfortunately, scholars of Tangut studies tend to focus on the Tangut versions and interpret those within the framework of their own field, publishing their results in specialised journals and forums. The dissemination of the results to wider audiences has been a relatively low priority and, as a result, scholars of Chinese philology are typically unaware of the significance and potential of this material for their own field. There are of course noteworthy exceptions, such as the Tangut Sunzi and Forest of Categories, which have been included in recent studies of the Chinese editions of these works by scholars not specialised in Tangut studies.

Yet the size of this corpus and the range of texts (known and unknown) would certainly merit the attention of the field of sinology. On a smaller scale, Sino-Tangut texts are similar to Chinese texts preserved in Japan, even though the latter are handed down in their original language (i.e. Chinese). They are a crucial addition to the texts that survive in China proper, as they give access to a number of long lost texts and unknown early editions. Since at least the late $19^{\text {th }}$ century, Chinese scholars have been aware of the existence of important manuscript copies and printed editions of Chinese books in Japan. Similarly, the examination of rare editions of Chinese books in libraries in Europe and North America during the course of the $20^{\text {th }}$ century has added valuable source material for the study of texts from nearly every period of Chinese history. Even in the $21^{\text {st }}$ century, one of the project initiated and sponsored by the NLC is the compilation of a comprehensive catalogue of extant Song editions in collections 
outside China. It is all the more surprising that Tang and Song works in Tangut translation remain unstudied except for a relatively small circle of scholars working in the narrow field of Tangut studies.

Clearly, the study of the Tangut books and manuscripts from Khara-khoto is still in its infancy. It is true that many of the texts have been transcribed and translated into Russian or Chinese but in most cases that was the extent to which they have been studied. While this preliminary stage of research is vital in making the material available for those who do not read Tangut, it is somewhat surprising how little attention these translations receive among scholars who would be able to benefit from them. It is my hope that the present book will help to make this group of texts known beyond the admittedly specialised field of Tangut studies and that Chinese and foreign scholars working on Chinese texts in general will recognise their value for their own research. 